\title{
Surface-based analysis of cortical thickness and volume loss in Alzheimer's disease
}

\author{
Emily lannopollo ${ }^{1}$, Ryan Plunkett ${ }^{1}$, Kara Garcia $^{2}$ \\ ${ }^{1}$ Indiana University School of Medicine, ${ }^{2}$ Indiana University School of Medicine, Department of \\ Radiology and Imaging Studies
}

Background and Hypothesis: Magnetic resonance imaging (MRI) has become a useful tool in monitoring the progression of Alzheimer's disease. Previous surface-based analysis has focused on changes in cortical thickness associated with the disease ${ }^{1}$. The objective of this study is to analyze MRI-derived cortical reconstructions for patterns of atrophy in terms of both cortical thickness and cortical volume. We hypothesize that Alzheimer's Disease progression will be associated with a more significant change in volume than thickness.

Experimental Design or Project Methods: MRI data was obtained from the Alzheimer's Disease Neuroimaging Initiative (ADNI). All subjects with baseline and two-year 3T MRI scans were included. Segmentation of MRIs into gray and white matter was performed with FreeSurfer ${ }^{2,3,4,5}$. Subjects whose scans did not segment accurately were excluded. Surfaces were then registered to a common atlas with Ciftify $^{6}$, and anatomically-constrained Multimodal Surface Matching (aMSM) was used to analyze longitudinal changes in each subject ${ }^{7}$. This produced continuous surface maps showing changes in cortical surface area and thickness. These maps were multiplied to create cortical volume maps ${ }^{8}$. Permutation Analysis of Linear Models (PALM) was used to perform two-sample t-tests comparing the maps of the Alzheimer's and control groups'.

Results: Preliminary analysis of nine Alzheimer's subjects and nine control subjects produced surface maps displaying patterns that were expected given previous research findings ${ }^{10,11}$. There was increased volume and thickness loss in Alzheimer's subjects relative to controls, with relatively high loss in structures of the medial temporal lobe. Future analysis of a larger sample will determine whether statistically significant differences exist between the Alzheimer's and control groups in terms of thickness loss and volume loss.

Conclusion and Potential Impact: If significant results are found, surface-based analysis of cortical volume may allow for detection of atrophy at an earlier stage in disease progression than would be possible based on cortical thickness.

\section{References}

1. Clarkson MJ, Cardoso MJ, Ridgway GR, Modat M, Leung KK, Rohrer JD, Fox NC, Ourselin S. A comparison of voxel and surface based cortical thickness estimation methods. Neurolmage. 2011 Aug 1; 57(3):856-65.

2. Dale AM, Fischl B, Sereno MI. Cortical surface-based analysis. I. Segmentation and surface reconstruction. Neuroimage. 1999;9:179194.

3. Fischl B, Sereno M, Dale A. Cortical surface-based analysis. II: Inflation, flattening, and a surface-based coordinate system. Neuroimage. 1999;9:195-207.

4. Fischl B, Salat DH, Busa E, Albert M, Dieterich M, Haselgrove C, van der Kouwe A, Killiany R, Kennedy D, Klaveness S, Montillo A, Makris N, Rosen B, Dale AM. Whole brain segmentation: automated labeling of neuroanatomical structures in the human brain. Neuron 2002;33:341-355.

5. Fischl B, Salat DH, van der Kouwe AJ, Makris N, Segonne F, Quinn BT, Dale AM. Sequence-independent segmentation of magnetic resonance images. Neuroimage 2004;23 Suppl 1:S69-84.

6. Glasser MF, Sotiropoulos SN, Wilson JA, Coalson TS, Fischl B, Andersson JL, Xu J, Jbabdi S, Webster M, Polimeni JR, Van Essen DC, Jenkinson M, WU-Minn HCP Consortium. The minimal preprocessing pipelines for the Human Connectome Project. Neuroimage. 2013 Oct 15;80:105-24.

7. Robinson EC, Garcia K, Glasser MF, Chen Z, Coalson TS, Makropoulos A, Bozek J, Wright R, Schuh A, Webster M, Hutter J, Price A, Cordero Grande L, Hughes E, Tusor N, Bayly PV, Van Essen DC, Smith SM, Edwards AD, Hajnal J, Jenkinson M, Glocker B, Rueckert D. Multimodal surface matching with higher-order smoothness constraints. Neuroimage. 2018;167:453-65.

8. Marcus DS, Harwell J, Olsen T, Hodge M, Glasser MF, Prior F, Jenkinson M, Laumann T, Curtiss SW, Van Essen DC. Informatics and data mining tools and strategies for the human connectome project. Front Neuroinform 2011;5:4.

9. Winkler AM, Ridgway GR, Webster MA, Smith SM, Nichols TE. Permutation inference for the general linear model. Neurolmage, 2014;92:381-397

10. Matsuda, H. MRI morphometry in Alzheimer's disease. Ageing Research Reviews. 2016 Sep;30:17-24.

11. Risacher SL, Shen L, West JD, Kim S, McDonald BC, Beckett LA, Harvey DJ, Jack CR Jr, Weiner MW, Saykin AJ. Alzheimer's Disease Neuroimaging Initiative (ADNI). Longitudinal MRI atrophy biomarkers: relationship to conversion in the ADNI cohort. Neurobiol Aging. 2010 Aug;31(8):1401-18. 